\title{
Information: Use and process whatever you can get!
}

\author{
Michael J. Zellweger, MD \\ a Cardiology Department, University Hospital Basel, University of Basel, Basel, Switzerland
}

Received Mar 29, 2021; accepted Mar 29, 2021

doi:10.1007/s12350-021-02638-2

\section{See related article, pp. 1870-1884}

The problems are solved, not by giving new information, but by arranging what we have known since long.

Ludwig Wittgenstein

In acute myocardial infarction and acute coronary syndromes, reperfusion therapy and revascularization by percutaneous coronary intervention (PCI) are the therapies of choice, clearly improving prognosis. ${ }^{1,2}$

In contrast, recent trials did not show prognostic benefit of revascularization over medical therapy in patients with chronic coronary syndrome. ${ }^{3-5}$

Therefore, it is more important than ever to select patients with chronic coronary syndrome for revascularization, appropriately.

Coronary anatomy and function provide complimentary information. A coronary artery stenosis may seem hemodynamically relevant by eyeballing but turns out not to reduce blood flow and vice versa. Thus, the "'oculo-stenotic'" reflex may lead to treacherous conclusions. As an example, in intermediate and equivocal left main coronary artery stenosis, functional significance of stenoses should not be based solely on angiographic assessment, even by experienced interventional cardiologists. ${ }^{6}$ Their estimates of stenosis severity were only correct in $39 \%$ to $57 \%$.

The Fractional Flow Reserve (FFR) versus Angiography for Guiding Percutaneous Coronary

Reprint requests: Michael J. Zellweger, MD, Cardiology Department, University Hospital Basel, University of Basel, Petersgraben 4, 4031 Basel, Switzerland; mzellweger@uhbs.ch

J Nucl Cardiol 2022;29:1885-6.

1071-3581/\$34.00

Copyright (C) 2021 American Society of Nuclear Cardiology.
Intervention trial (FAME trial) demonstrated that routine measurement of FFR in patients with multivessel coronary artery disease who were undergoing percutaneous coronary intervention (PCI) with drug-eluting stents significantly reduced the rate of the composite endpoint of death, nonfatal myocardial infarction, and repeat revascularization at 1 year. $^{7}$

Ideally, only patients with evidence of ischemia documented by non-invasive tests or with a high pretest probability are referred to coronary angiography. If coronary angiography reveals stenoses which fit the localization of ischemia assessed by a non-invasive test, then about the same condition has been fulfilled as described in the FAME trial with FFR. Interestingly, for the most part, FFR, when it was first used, was validated by myocardial perfusion SPECT.

If patients do not suffer from single but multi-vessel disease or if they had undergone coronary artery bypass graft surgery, allocation of the ischemic region to a particular vessel can be tricky.

In this regard, hybrid imaging or fusion imaging may help to identify the "culprit vessel" or the "culprit stenosis" (e.g., computed tomography coronary angiography combined with SPECT or PET perfusion). However, most of the patients do not undergo hybrid imaging.

Therefore, the "3D Fusion between fluoroscopy angiograms and SPECT myocardial perfusion images to guide percutaneous coronary intervention' trial by Tang et al. ${ }^{8}$ is an important example how to combine (already existing) data for decision making in the cath lab and how available data should be used and combined, also using artificial intelligence approaches, as appropriate: coronary angiography was used to reconstruct 3D artery anatomy. SPECT imaging results were used to define the left ventricular surface. This deep learning-driven approach may then allow to better align anatomic stenosis by coronary angiography with perfusion abnormalities assessed by SPECT (or other modalities in the future). The methodology of the deep learning 
approach and the models used for reconstruction are based on meticulously applied analytical and mathematic methods which probably are far beyond the understanding of the clinical cardiologist and cardiac imager (including me). Therefore, it is of utmost importance that methods and models as suggested in the study by Tang et al. ${ }^{8}$ are tested and validated by computer simulation and in daily practice.

The suggested algorithm provides the fusion results within an average processing time of 5 minutes which may be acceptable even in a busy cath lab. But, even though computers and software provide undeniable additional value in most fields of cardiology, a fiveminute waiting time is still challenging our patience during an invasive procedure. Unfortunately, even a considerable amount of the commercially available software distributed by the largest vendors is quite disappointing when it comes to efficiency and userfriendliness.

With respect to accuracy, the clinical evaluation with 30 patients, 3D fusion had mismatch errors ranging from $3.84 \pm 3.15 \mathrm{~mm}$ to $5.55 \pm 3.64 \mathrm{~mm}$, which is smaller than the segment size of the AHA 17-segment model. If these results held true in daily practice, these fusion images may find broader use. Furthermore, the principles and techniques themselves may also be applied in other fields (e.g., fusion of coronary arteries as assessed by coronary CT angiography and SPECT or PET; cardiac magnetic resonance data and fluoroscopy in the cath lab, especially in the field of electrophysiology, etc.).

In summary, the current study nicely demonstrates that data acquired by different imaging modalities can and should be combined with the goal to accumulate and use the most accurate information available to solve a problem. As in the case of the current study by Tang et al. ${ }^{8}$ artificial intelligence approaches facilitate the timely merging process of anatomic and functional information in the chronic coronary syndrome setting which might help to carry out the most appropriate revascularization procedures.

\section{Disclosure}

There is no conflict of interest.

\section{References}

1. Nabel EG, Braunwald E. A tale of coronary artery disease and myocardial infarction. N Engl J Med 2012;366:54-63.

2. Pedersen F, Butrymovich V, Kelbæk H, Wachtell K, Helqvist S, Kastrup J, et al. Short- and long-term cause of death in patients treated with primary PCI for STEMI. J Am Coll Cardiol 2014;64:2101-8.

3. Boden WE, O'Rourke RA, Teo KK, Hartigan PM, Maron DJ, Kostuk WJ, et al. Optimal medical therapy with or without PCI for stable coronary disease. N Engl J Med 2007;356:1503-16.

4. Frye RL, August P, Brooks MM, Hardison RM, Kelsey SF, MacGregor JM, et al. A randomized trial of therapies for type 2 diabetes and coronary artery disease. N Engl J Med 2009;360:250315 .

5. Maron DJ, Hochman JS, Reynolds HR, Bangalore S, O’Brien SM, Boden WE, et al. Initial invasive or conservative strategy for stable coronary disease. N Engl J Med 2020;382:1395-407.

6. Lindstaedt M, Spiecker M, Perings C, Lawo T, Yazar A, HollandLetz T, et al. How good are experienced interventional cardiologists at predicting the functional significance of intermediate or equivocal left main coronary artery stenoses? Int J Cardiol 2007;120:25461.

7. Tonino PA, De Bruyne B, Pijls NH, Siebert U, Ikeno F, van' t Veer $\mathrm{M}$, et al. Fractional flow reserve versus angiography for guiding percutaneous coronary intervention. N Engl J Med 2009;360:21324.

8. Tang H, Bober RR, Zhao C, Zhang C, Zhu H, He Z, et al. 3D fusion between fluoroscopy angiograms and SPECT myocardial perfusion images to guide percutaneous coronary intervention. J Nucl Cardiol 2021. https://doi.org/10.1007/s12350-021-02574-1.

Publisher's Note Springer Nature remains neutral with regard to jurisdictional claims in published maps and institutional affiliations. 